\title{
A ESCRITA COMO ARTESANATO: A EXPERIÊNCIA DO ESCREVER(-SE)
}

\author{
Adriana Werneck Russo Muniz ${ }^{\mathrm{i}}$ \\ Karine Oliveira Bastos ${ }^{\text {ii }}$ \\ Luiz Antônio Saléh Amado ${ }^{\mathrm{iii}}$
}

\begin{abstract}
RESUMO: Um exercício de escrever(-se) "para não ser mais o mesmo" (FOUCAULT, 2010). Ao trazermos, para a composição deste artigo, escritas-anotações tecidas no território da academia, objetivamos expor efeitos e deslocamentos produzidos com o ato de escrever, como etopoiética, nos espaços institucionais de produção de conhecimento. Pensamos sobre o processo de produção de nossas escritaspesquisas no campo educacional - que não se pretendem prescritivas, senão interrogativas de certas verdades - ao mesmo tempo em que somos convocados ao exercício estético do cuidar de si. Nessa aposta ético-política, nos aproximamos de uma escrita inspirada na problematização das relações entre a escrita de si e o cuidado de si, trazidas por Foucault (2004), e na noção de experiência, apresentada por Larrosa (2015).
\end{abstract}

Palavras-chave: escrita de si; cuidado de si; etopoiética; experiência.

\section{THE WRITING AS HANDICRAFT: THE EXPERIENCE OF WRITING (ONESELF)}

\begin{abstract}
An exercise of writing (oneself) "to no longer be the same" (FOUCAULT, 2010). By bringing writings-notes to this paper, produced in the academic territory, we aim to expose effects and displacements produced with the act of writing, as etopoietic, in institutional spaces of knowledge production. We think about the production process of our writings-researches in the educational area which are not intended to be prescriptive, but interrogative of certain truths - at the same time that we are summoned to the aesthetic exercise of care of oneself. In this ethical-political bet, we approach a writing inspired by the problematization of the relations between writing of oneself and care of oneself, brought by Foucault (2004), and to the notion of experience, presented by Larrosa (2015).
\end{abstract}

Keywords: writing of oneself; care of oneself; etopoietics; experience

Carolina anota. Relata, em cadernos, o dia. Tentativas de capturar o dito, o ouvido, o vivido. Escrever-(se) com a fome, a vida, o mundo, o lápis. Um exercício de escrever-(se) “para não ser mais a mesmaiv".

De manhã eu estou sempre nervosa. Com medo de não arranjar dinheiro para comprar o que comer. Mas hoje é segunda-feira e tem muito papel na rua. (...) O senhor Manuel apareceu dizendo que quer casar-se comigo. Mas eu não quero porque já estou na maturidade. E depois, um homem não há de gostar de uma mulher que não pode passar sem ler. E que levanta para escrever. E que deita com lápis e papel debaixo do travesseiro. Por isso é que eu prefiro viver só para o meu 
ideal. Êle deu-me 50 cruzeiros e eu paguei a costureira. Um vestido que fez para a Vera. A Dona Alice veiu queixar-se que o senhor Alexandre estava lhe insultando por causa de 65 cruzeiros. Pensei: Ah! O dinheiro! Que faz morte, que faz odio criar raiz". (JESUS, 2001, p. 44) ${ }^{\mathrm{v}}$

Anotações são palavras menores ${ }^{\mathrm{vi}}$. Situam-se no avesso dos textos que tornamos públicos. Produzir anotações é permitir-se à processualidade da escrita. Anotamos o que nos passa; o que nos acontece fragmentos de textos lidos, captura de frases ouvidas, compromissos firmados, impressões. Não são assépticas. Permitem-se o sujar da folha, rascunhar-se sobre as palavras. Anotações, escrita transitória e

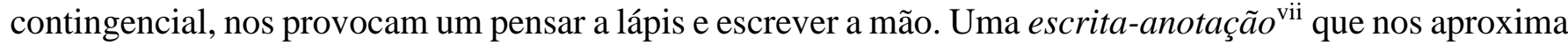
a uma certa escrita "Carolina":

Foucault, a escrita de si e uma certa escrita Carolina

Carolinizar-se não é escrever sobre a fome; tampouco escrever apesar da fome.

Carolinizar-se é escrever com a fome.

Com e em companhia de aquilo que nos inquieta.

Carolinizar-se é um escrever meio torto.

É permitir-se. É o ato de escrever duro e solto.

É escrever com a vida que nos pertence.

Carolinizar-se requer a coragem de uma escrita menor.

Uma escrita dia a dia.

Sem ao menos, ao final do dia, saber que palavras comporão o outro dia.

Carolinizar-se é ter palavras no estômago.

Digerir algumas e cuspir outras.

É fazer do presente: palavras.

É fazer das palavras, presença.

Carolinizar-se é também mundanizar-se.

É pertencer à fome do mundo, às dores do mundo, às artes do mundo, às incompletudes do mundo.

Carolinizar-se é tomar do outro as palavras e fazê-las suas.

Ao fazê-las suas, já não mais te pertencem.

Carolinizar-se é um movimento não retilíneo.

Carolina escreve as palavras e as palavras escrevem Carolina.

Carolinizemo-nos.

Mas por que começamos o texto "puxando conversa" sobre anotações? Como fragmentos de aula, rascunhos, versos se inserem neste escrito? Afinal, a que se pretende este texto? Antecipadamente, vale dizer que "a que se pretende este texto" é questão que se constrói, de fato, a partir da perspectiva de quem escreve e não necessariamente de quem lê. Em outras palavras, o processo de leitura, inclusive o nosso, extrapola qualquer pretensão prévia, porque alcança outros contornos, outras possibilidades. É 
provável - e desejado - que o escrito se perca, se misture a outras leituras, outros escritos, outros conceitos. Trata-se, portanto, de um texto produzido em pontos abertos, soltos, capazes de se desmancharem.

\section{Ponto de provocação}

Este texto foi produzido a partir de um convite-provocação feito pelos professores Estela Scheinvar e Luiz Antônio Saléh Amado durante a disciplina A pesquisa e a escrita como construção se si, do Programa de Pós-Graduação em Políticas Públicas e Formação Humana (PPFH), da Universidade do Estado do Rio de Janeiro (UERJ). Fomos provocados a escrever e (com)partilhar textos, sem formato prévio, que expusessem nossas percepções, afetações, problematizações e entendimentos produzidos na e a partir da leitura dos textos propostos para a disciplina. Leituras de Foucault (1999; 2003; 2004), Ó (2019), Rolnik (1993), Deleuze (2005), Fischer (2012), Costa (2002), Peters (2000).

A partir delas, produzíamos fragmentos, versos, prosas, rascunhos, crônicas, bordados, ressonâncias, transbordamentos. Uma produção que se inscreveu em dobras: torceu as palavras dos outros, criou palavras contingenciais, passageiras e sem autoria. Torcíamos as palavras; torcíamo-nos sobre as palavras como as lavadeiras de Alagoas:

Deve-se escrever da mesma maneira com que as lavadeiras lá de Alagoas fazem em seu ofício. Elas começam com uma primeira lavada, molham a roupa suja na beira da lagoa ou do riacho, torcem o pano, molham-no novamente, voltam a torcer. Colocam o anil, ensaboam e torcem uma, duas vezes. Depois enxaguam, dão mais uma molhada, agora jogando água com a mão. Batem o pano na laje ou na pedra limpa, e dão mais uma torcida e mais outra, torcem até não pingar do pano uma só gota. Somente depois de feito tudo isso é que elas dependuram a roupa lavada na corda ou no varal, para secar. Pois quem se mete a escrever devia fazer a mesma coisa. A palavra não foi feita para enfeitar, brilhar como ouro falso; a palavra foi feita para dizer. (RAMOS, 2005)

Escrita como estilo e como estética: arriscava-nos, em agonística ${ }^{\text {viii }}$, em uma academia que está por vir, em vias de existir. Experimentávamos, a cada aula, nossas próprias escritas, os compartilhamentos, as sensações, as escutas. Um movimento que, de alguma maneira, provocava intolerância às aulas-verdade e às meta-narrativas iluminadas. Uma intolerância à maneira foucaultiana: “atribuída àquilo que, para a maioria das pessoas (ou, ao menos, nos discursos e práticas hegemônicos), é considerado natural" (RODRIGUES, 2015, p. 119).

A escrita - corpo-prática inserida em relações com outros corpos - não foi tomada como reflexo das existências, tampouco como descrição dessas. Sendo ela mesma corpo-experiência, produzia, atuava sobre e deslocava corpus de experimentações, afinal, aquilo que denominamos "escrita acadêmica" não é da ordem da naturalidade, mas está atrelado a regimes de verdade. Menos do que instrumento em si 


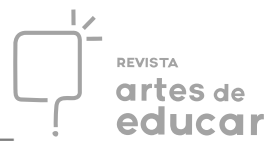

mesma, a escrita na e $d a$ academia/pesquisa (teses, diários, manuais, métodos, normas, análises, verificação, artigos, resultados) é uma construção para a qual contribui uma série de discursos que engendram diferentes verdades.

Afetávamo-nos com uma escrita artesanal, cotidiana, produzida com o outro. Com o exercício de tecer uma escrita sobre a escrita tal qual o artista que produz um quadro de bordados ${ }^{\mathrm{ix}}-$ intitulado Mulheres que bordam entre rios ${ }^{\mathrm{x}}$ - que retrata o próprio ato cotidiano do bordar.

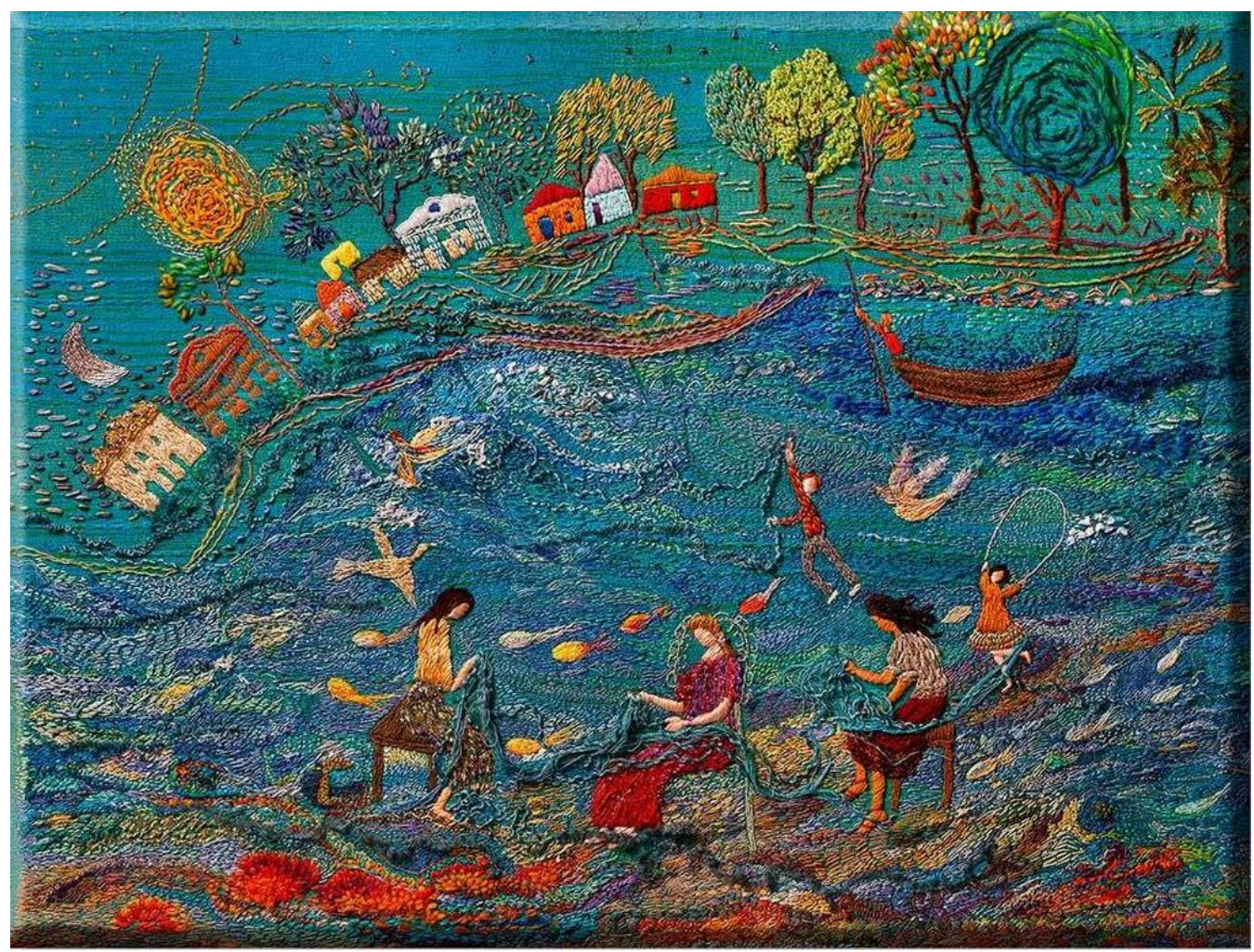

Fonte: Dumont (2020)

Produzíamos e compartilhávamos escritos que atuavam sobre aqueles que escreviam, no próprio ato de escrever, e sobre os que os escutavam. Uma escrita que se reinventou etopoiética - aqui denominadas escritas-anotações. E são nossas escritas-anotações - espalhadas pelo texto - que se forjam como fio condutor deste artigo: memórias transbordantes de escreventes ${ }^{\mathrm{xi}}$ que, na produção de uma escrita de si, produzem o exercício do "cuidar de si”, conforme nos provoca Foucault (2006): "é preciso que te ocupes contigo mesmo, que não te esqueças de ti mesmo, que tenhas cuidado contigo mesmo" (p. 6).

Ao trazermos para a composição deste artigo as escritas-anotações, produzidas $\mathrm{na} / \mathrm{com}$ o território $^{\text {xii }}$ da academia, não intencionamos desvelar verdades, prescrever a melhor forma de produzir pesquisas ou mesmos manuais criativos de escritas. Por outro caminho, fazemos uma aposta ético-política em modos de escrever(-se) que, desviando-se da busca por uma pretensa neutralidade e expondo o "avesso 
da tapeçaria"xiii, podem produzir práticas singulares de pensamento que interrogam o sujeito no interior de práticas hegemônicas de produção de conhecimento.

\section{Ponto de ressonância}

Entrelaçada a essa aposta, um objetivo como ponto de ressonância: expormos os efeitos e deslocamentos produzidos com o ato de escrever, como etopoiética, nos espaços institucionais de produção de conhecimento, tais quais a academia e a escola. Escritas que não se pretendem prescritivas, mas que potencializam a suspensão/interrogação de certas verdades e palavras (co)engendradas nas práticas educacionais. Um exercício de pensar o processo de produção de nossas escritas-pesquisas no campo educacional ao mesmo tempo em que somos convocados ao exercício estético do cuidar de si mesmo.

Nessa aposta ético-política, nos aproximamos de uma escrita inspirada na problematização das relações entre a escrita de si e o cuidado de si trazida por Foucault (2004) e na noção de experiência apresentada por Larrosa (2015). A tessitura do texto é feita, ainda, com outros encontros que nos passaram, em afectos $^{x i v}$. Destacamos dois livros que chegaram às nossas mãos durante a disciplina: Escritas de Si: Escutas, cartas e formação inventiva de professores entre universidade e escola básica (DIAS; RODRIGUES, 2019) e Análise Institucional, Genealogia, História Oral: fabricando intercessores em pesquisa e intervenção (RODRIGUES, 2019). Além disso, tivemos a aula ministrada pela professora Kátia Aguiar $^{\mathrm{xv}}$ que, de maneira generosa, nos proporcionou uma aproximação às Conversações, de Deleuze, e as falas desconcertantes de Jorge Ramos do Ó $^{\mathrm{xvi}}$ sobre uma escrita inventiva e anti-normativa na universidade.

Intercessores que inspiram o segundo ponto deste artigo: a escrita como ferramenta de um fazer-(se) a mão. Uma prática escritural, cotidiana e cuidadosa, que potencializa a produção de uma estética da existência. Algo como o exercício de um artista que borda, em pontos artesanais, uma tapeçaria.

\section{Pontos artesanais: fazer (-se) a mão}

Por onde começar a parte da conversa em que nos dispomos a abrir nossa caixa de $\operatorname{artesanatos}^{\mathrm{xvii}}$ - ferramentas conceituais com as quais bordamos o texto - e expor os modos pelos quais as operamos?

Decidimos começar pela apresentação de duas opções político-estéticas de própria produção deste texto. A primeira delas é que nossa escrita se reivindica ensaio. Ensaio como descreve Larrosa (2004): “dar forma a uma experiência do presente [...] é o que nos acontece agora, quem somos agora, o que podemos pensar e o que podemos dizer e o que podemos experimentar agora, neste exato momento da história (p. 34)". Outra é que ela se interessa pelo exercício de "dizer coisas". Coisas sempre processuais, 
abertas, reconectáveis. Uma aproximação a Foucault (2016, p. 69) : "Não tenho de modo algum a impressão, nem mesmo a intenção, de fazer uma obra. Tenho um projeto de dizer coisas."

Escrita do presente. Ensaiada, também, nas anotações do caderno de aula. Quando experimentada, em versos, configurou-se na escrita de Cartas ao Mar ${ }^{\text {xviii }}$.

\section{Cartas ao mar}

Escrevo como quem joga cartas ao mar.

Cartas a ninguém. Cartas ao mundo.

Cartas sem destinatários. Cartas sem autor.

Cartas que não pertencem ao remetente.

Elas o antecedem.

Quem as escreve apenas rouba as palavras do mundo

Ao roubá-las, não mais as possui.

Cartas sem destinatário.

Mas, se há algum conforto para quem as escreve, talvez, seja este: elas podem afetar os que se aproximam do mar.

Os que gostam das imprevisibilidades das ondas.

Os que observam a complexidade das marés que,

na repetição diária de seus movimentos,

nunca trazem, para a orla, o mesmo do mar.

Cartas escritas ao mar são produzidas a partir da cotidianidade do presente;

com a imprevisibilidade do presente

e nos deslocamentos no presente.

Não são despretensiosas.

Provocam deslocamentos - em quem escreve e no escrito.

De certa maneira, potencializam a realização de um difícil exercício:

o de estranhar-se a si mesmo.

Feito essa espécie de preâmbulo político-estético, voltemos (ou continuemos?) à nossa caixa de artesanatos. Dela, retiramos as análises trazidas por Foucault (2004), no artigo A Escrita de Si, como base de apoio para tratar a questão da escrita como cuidado de si.

O cuidado de si foi um tema amplamente apresentado por Foucault (2006) - no curso $A$ Hermenêutica do Sujeito (1982) - quando, em sua empreitada genealógica de fazer uma história da subjetividade - os modos pelos quais nos tornamos sujeitos -, o filósofo mira o olhar em direção à antiguidade greco-romana. Segundo o próprio filósofo, (FOUCAULT, 2004, p. 141), o referido artigo “parte de uma série de estudos sobre as 'artes de si mesmo', isto é, sobre a estética da existência e o governo de si e dos outros na cultura greco-romana, nos dois primeiros séculos do Império".

Dentre as práticas filosóficas realizadas, seja pelos gregos ou romanos, para o cuidado de si, está a "escrita de si", enquanto uma "tecnologia de si" que os sujeitos históricos dispõem como possibilidade de ascese - "adestramento de si por si mesmo" (FOUCAULT, 2004, p. 144) no pensamento. Tecnologias que potencializam a vida como de estética da existência, isto é, a vida como uma obra de arte. 
Para o exercício da ascese, praticado na Antiguidade, se colocam - conforme analisa Foucault - a correspondência e o hypomnemata. Esta última se configurava como uma espécie de caderneta de anotações, que, na Antiguidade, era utilizada para o registro de leituras, pensamentos, afetações e questionamentos que lhes ocorriam em suas cotidianidades. Em outras palavras, um "livro de vida" ou "guia de conduta", uma memória material das coisas ouvidas ou pensadas, um material que poderia ser utilizado para o exercício do ler, reler, meditar, do cuidar-se. Uma prática escritural que não deveria ser tomada como um mero auxiliar de memória, mas que constituísse em instrumentos que pudessem estar "a mão" com apoio em diferentes ocasiões da vida (FOUCAULT, 2004).

"A mão", portanto, não apenas no sentido de poderem ser trazidos à consciência, mas no sentido de que se deve poder utilizá-los, logo que necessário, na ação. Tratase de constituir para si próprio um logos boethikos, um equipamento de discursos a que se pode recorrer, susceptíveis - como diz Plutarco - de erguerem eles próprios a voz e de fazerem calar as paixões, como o dono que, com uma só palavra, sossega o alarido dos cães. (FOUCAULT, 2004, p. 146).

As escritas-anotações - produzidas em leituras, meditações, cotidianidade, releituras - se configuraram como uma prática escritural de hupomnêmata. No entanto, em tempos de Coach, livros de autoajuda, individuação, tecnologias do eu ${ }^{\mathrm{xix}}$, esclarecemos que o exercício da escrita do hupomnêmata não é "a "narrativa de si mesmo"; não tem como objetivo esclarecer os arcana conscientiae $e^{x x}$, cuja confissão oral ou escrita - tem valor de purificação" (idem, 148). O processo da escrita e do cuidar-se com a escrita segue um caminho distinto: “trata-se não de buscar o indizível, não de revelar o oculto, não de dizer o nãodito, mas de captar, pelo contrário, o já dito; reunir o que se pôde ouvir ou ler, e isso com uma finalidade que nada mais é que a constituição de si (ibidem, 149)".

Hara (2012), seguindo as análises de Foucault, apresenta a escrita de si e a confissão de si como duas estratégias claramente opostas:

A confissão de si tinha como meta dizer o indizível. Revelar o oculto. Essa narrativa estava voltada para dentro, para o interior do sujeito. A pergunta, de fundo, é 'quem sou eu' ou 'o que sou de verdade'? O sujeito olha para o seu interior, e relata quem ele é. [...] No caso dos gregos, da escrita de si, você percebe que o movimento é contrário. Seus olhos estão voltados para fora, para o mundo exterior. Você está captando, selecionando, escrevendo e incorporando, subjetivando, tornando seu pensamento, discursos, princípios, exemplos que estão fora de você. São essas representações do mundo exterior que ajudam a dar forma ao seu interior. (HARA, 2012, p. 110).

Nossas anotações, nessa direção, se estabelecem como uma escrita etopoiética: "operadora da transformação da verdade em ethos" (FOUCAULT, 2004, p. 147). Escritas que nos passam na heterogeneidade do entre. Entre o experimentar, o escrever, o ensaiar, o interrogar, o cuidar (de si e do 
outro), o estranhar, o fillosofar, o produzir. Um entre "tomado" das análises de Deleuze (1992, p. 154): "o que me interessa são as relações entre as artes, a ciência e a filosofia. Não há nenhum privilégio de uma destas disciplinas em relação a outra.” Algo que nos remete à imagem que Larrosa (2004) constrói em seu diário durante uma primavera em Paris: um movimento entre a estante e a mesa; entre a leitura e a escrita.

Passo as manhãs com Foucault e as tardes com Montaigne. Me interessa o que dizem, claro, mas me interessa, acima de tudo, seu modo de escrever e de ler, suas reflexões sobre a escrita e a leitura. O que eu gosto é de passar as manhãs com Foucault em sua biblioteca, com seus livros, com os livros que ele lia, que ele citava, em relação aos que ele pensava... E passar as tardes com Montaigne, imaginando$\mathrm{o}$, também, em sua biblioteca, nesse movimento quase enlouquecido entre as estantes que armazenam a leitura e a mesa que centra a escrita. (LARROSA, 2004, p. 30; grifos nossos).

Uma escrita que nos passa como espaço da experiência. Não a experiência de um sujeito transcendental ou cognoscente; ou ainda, a experiência existencial ou individual. Mas uma noção de experiência, tal qual formulada por Larrosa (2015): “A experiência é o que nos passa, o que nos acontece, o que nos toca. Não o que se passa, não o que acontece, ou o que toca” (p.18). Uma experiência em que o sujeito não a precede, mas se forja nela - sujeito da experiência. Esse sujeito da experiência "seria algo como um território de passagem, algo como uma superfície sensível que aquilo que acontece afeta de algum modo, produz alguns afetos, inscreve algumas marcas, deixa alguns vestígios, alguns efeitos" (LARROSA, 2015, p. 22).

Nessa perspectiva, a escrita, ela mesma como corpus de experimentações, se instaura em complexas e interconectadas redes de escrita/sujeito/história. Uma escrita tecida com o crochê, a costura, a fábrica, a casa, o dentro, o fora ${ }^{\mathrm{xxi}}$.

Escrever como artesanato.... Por que algo que parece tão simples nos toca tão complicado? Seria simples: é só cozer, pontuar, pintar a mão, esculpir, amarrar...Mas não é. Será que "perdemos a mão" do fazer artesanal? Será que nos perdemos no fazer de uma vida autoral?

$[\ldots]$

Jorge continua falando de uma escrita inventiva. De uma fazer a mão. Parece-me uma "escrita-menor". Isso me lembra o trabalho das mulheres com as quais eu convivi. Minha mãe fazendo crochê; tia Lili transformando retalhos em tapetes; vó Dita tricotando; vó Cidinha consertando roupas. Eu sempre admirei esse trabalho delas. Era feito ali: no perto da gente, na casa, no dia a dia. Mas reconheço que esse fazer era tido como um trabalho menor. $O$ trabalho maior era o feito, em geral, pelos homens nas fábricas e no departamento. Minha mãe sempre se apresentava como enfermeira. Por que não como uma exígua "crocheteira"? (Sei que essa palavra não existe. Pelo menos, não existiu até agora...). Talvez com a minha escrita seja assim: uma para dentro e outra para fora. 
Escrever sobre/com anotações, como função etopoiética, trata-se, portanto, da experimentação com a escrita de um olhar "a nós mesmos - pesquisas/pesquisadores. Um olhar que não procura "coisas absolutamente escondidas, camufladas, esquecidas" [...] nem que faça "aparecer o que está muito imediatamente presente e ao mesmo tempo invisível", mas um olhar que se volta para "o que está próximo demais de nosso olhar para que possamos ver, o que está aí bem perto de nós, mas que nosso olhar atravessa para ver outra coisa [...] devolver sua intensidade e sua espessura àquilo que costumamos experimentar como transparência (FOUCAULT, 2016, p. 69).”

Um complexo processo de pensar a escrita, suas possibilidades e armadilhas, com o escrever em ato. Afinal, como nos disse Jorge Ramos do Ó (ou, ao menos, foi assim que suas palavras nos passaram): a de que é no interior da produção escrita que compreendemos os próprios processos escriturais. Escrever no intento, não de olhar para quem nós somos, mas de uma mirada presbita sobre "o que se passa conosco" no presente e, assim, (talvez) forjar estratégias poéticas como estéticas do cuidar de si.

\title{
Pontos alinhavados: do começo ao fim (ou) do fim ao começo
}

\author{
Morena de Angola que leva o chocalho \\ amarrado na canela \\ Será que ela mexe o chocalho \\ ou o chocalho é que mexe com ela?
}

(HOLLANDA, 1982)

Interpretada pela cantora Clara Nunes e composta por Chico Buarque de Hollanda, a canção "Morena de Angola", ouvida por uma das autoras durante o trajeto de trem até a UERJ, nos remete não só ao ir e vir da cidade como a outras trajetórias: as que, por vezes, ganham contornos cíclicos, embaçando os limites do que conhecemos por começo e por fim, desbotando definições de causa-efeito com as quais habitualmente sustentamos nossas ideias.

Desse modo, a escrita deste trabalho ora se configura como o relato de um "cursar" na academia, ora se sustenta em referências teóricas, ora abre espaço para a palavra que se permite artística, ora delimita como citação o exercício nosso de escrita como experiência. No entanto, caminhando com "chocalho amarrado na canela", a escrita de si reivindica (aqui) outra configuração, que possa esta - concedida pelo "fluxo contínuo" - aumentar fontes, reduzir margens.

Escrevendo sobre a escrita na perspectiva dos pontos alinhavados - e, portanto, abertos, soltos -, consideramos outras possibilidades de tessitura no tempo do "agora", não só "puxando conversa" sobre anotações, mas desmanchando limites entre escrita do passado e escrita do presente assim como ensaiando - em sua definição processual, metafórica e também denotativa do próprio gênero “ensaio". 
Eis o mote: uma professora de Português, que aprende e ensina sobre o processo da escrita, que ocupa o "entre" da escola e da academia, espaços institucionais de produção do conhecimento. Escrevendo sobre a escrita, os deslocamentos são produzidos à medida que certas verdades vão sendo questionadas (entre parênteses, interrogações e reticências).

\section{Pontos da escrita: entre parênteses, interrogações e reticências}

O silêncio que antecede o "primeiro" parágrafo anuncia - ou denuncia - o desconforto diante de um suposto começo do texto acadêmico. Diante de tantas interrogações, impossível não abrir parênteses diversos, que movimentam, metalinguisticamente, questões a respeito da escrita de si. Isso posto, que não faltem a esta trajetória possibilidades de reticências.

Há uma indagação recorrente em sala de aula por alunos a uma professora que, teoricamente, possa lhes oferecer uma resposta. "Professora, como começo meu texto?". Está aí o "branco", como costumam definir este momento pré-escrita. Está aqui o "branco" de uma professora que já não tem resposta bem definida como outrora. Talvez este "branco" - silêncio - fosse naturalizado como parte do processo de escrita, mas, neste momento, é o ponto que me faz parar o ritmo de algumas convicções oriundas da minha formação, me permitindo sentir os efeitos de um som que emerge por outros ângulos. Em outras palavras, o silêncio me chama, agora, em alto e bom som.

Pensar o começo da escrita de um texto sugere, antes disso, dar foco a seu planejamento, em que se possa definir "o que", "como" e "para quem" escrever. A questão é que conteúdo e forma (estão) categorias dissolvidas no meu processo de pensar os percursos da pesquisa e da escrita como construção de si.

Nesse contexto, desconfio que, quando uma atividade de produção textual é proposta em sala de aula e algum aluno pergunta "professora, como começo?", este não esteja se referindo à forma ou ao conteúdo do texto em si, mas talvez ao modo como pode se entregar ao processo de escrita.

Não há, a priori, uma resposta previsível a esta pergunta, isto é, algo do âmbito escolar e universitário que funciona mais como enquadramento de uma escrita a gêneros textuais ditos acadêmicos e que geralmente nos proporciona a sensação de lermos em série o mesmo texto. De outro modo, a esta pergunta apresento outra, semelhante e paralela. Como iniciar esse exercício de escrita de si, avaliação final de disciplina de doutorado?

Muito embora "o que" (conteúdo), "como" (forma) e "para quem” escrever sejam (ainda) pontos de atenção - e tensão - a cada parágrafo, faço a aposta de uma trajetória da escrita na perspectiva do imprevisível, isto sim, algo (já) distante das orientações que eu tenha recebido e oferecido em sala de aula.

Na perspectiva do imprevisível, curiosamente, tenho me orientado - ou me inspirado - no decorrer do meu doutorado e, especialmente, durante as aulas desta disciplina pela definição da filósofa Viviane 
Mosé: "poema é construção, poesia é presença" (2017). Digo “curiosamente”, porque não imaginava fazer tal correlação justamente no decorrer de uma trajetória - digamos - acadêmica. Digo "curiosamente" também, porque, diante da exigência de uma intensa produção escrita em prosa, aparentemente nada poética, noto a fragilidade de delimitações como, por exemplo, conhecemos entre forma e conteúdo.

Portanto, estou presente e essa presença é "poética" - porque adjetiva - mas, sobretudo, "poesia" porque substantiva. Do mesmo modo, exercito a escrita - para além do que se possa convencionar a respeito de forma (poema / prosa) - como "construção de si".

Assim, a imagem retilínea envolvendo meta, início e fim não (mais) se sustenta. A propósito, outra inspiração dos últimos tempos, a canção "Metáfora”, de Gilberto Gil, anuncia: "Uma meta existe para ser um alvo / Mas quando o poeta diz 'meta'/ Pode estar querendo dizer o inatingível".

Buscando entender mais sobre o debate teórico-metodológico do pós-estruturalismo, foi bastante interessante notar, no tópico que relaciona pós-estruturalismo com estruturalismo, a importância da linguística estrutural como base para o estruturalismo francês do século XX. Ferdinand Saussure, por exemplo, conhecido como pai da linguística moderna, por meio de estudo sincrônico, apresenta a linguagem como sistema de significação, cujos elementos se submetem a relações internas, o que sugere a autonomia e totalidade desse sistema. O linguista é muito conhecido por estabelecer relações dicotômicas entre "la parole" (fala real) e "la langue" (sistema formal de linguagem), significante (forma acústica da palavra) e significado (conceito / conteúdo), sincronia e diacronia, sintagma e paradigma.

Mesmo que seus estudos sejam referência como base / origem da linguística moderna, de uma forma mais geral, do estruturalismo francês do século XX e, portanto, tenham sofrido inúmeras críticas e atualizações conceituais ao longo dos anos por correntes teóricas subsequentes, o que mais me marcou no decorrer do debate foi notar o quanto de estruturalista temos em nosso modo de pensar. Nesse sentido, duas noções me impactaram mais no movimento de refletir sobre os percursos da pesquisa: totalidade e dicotomia.

A ideia de totalidade me remete a um olhar que necessita abarcar todos os cantos de um determinado campo, por garantia de percorrer sobre terreno conhecido, de modo que não restem questões não respondidas. Tal imagem sugere um universo de vigilância, no qual não se pode correr riscos, e não se pode abrir portas nem brechas para o desconhecido.

A totalidade envolve caminho retilíneo e previsível, que parte do início e chega ao fim, muito provavelmente, confirmando hipóteses previamente estabelecidas e anunciadas. Assim, conhecemos um modo de fazer pesquisa que exige do pesquisador abraçar o todo que supostamente exista, evitando aproximações e tangenciamentos com o que possa haver além desse "todo".

A escrita, nesse contexto, configura-se representativa dessa totalidade, sobretudo porque obedece a uma série de regras formais pré-estabelecidas pela academia de modo geral e por especificidades de 
determinados campos teóricos. Certamente, não faltam manuais especialmente orientados por profissionais de Letras, que delimitam as possibilidades da "escrita do texto acadêmico", por exemplo. Um determinado manual se utiliza da imagem do mapa da linha 1 do metrô da cidade do Rio de Janeiro (retilínea) como metáfora para ilustrar o caminho "correto" da linha argumentativa de uma pesquisa, reprovando, ao mesmo tempo, a imagem das linhas de metrô de Paris, que apresentam inúmeras ramificações, conexões e são marcadas, evidentemente, por um sistema de transporte público com maior complexidade, para não dizer eficiência.

A ideia de dicotomia também se apresenta de muitos modos: fala versus escrita, forma versus conteúdo, teoria versus prática, poesia versus prosa, texto literário versus texto acadêmico, denotação versus conotação. É desafiante, inclusive, elaborar outras imagens que se desvinculem dessa lógica.

No decorrer dos meus estudos linguísticos, muitas vezes, no movimento de rever as relações no âmbito da dicotomia, me aproximei mais da imagem de contínuo, por exemplo, entre fala e escrita, considerando, nesse caso, as diferentes práticas sociais de produção textual em que estas modalidades estejam inseridas. No entanto, buscando um caminho pós-estruturalista, surge a necessidade de conhecer outras imagens, outros mapas, outras rotas e, especialmente, outros transportes que possam dar conta de outros modos de pensamento, para além do "ir e vir" estruturalista que ainda nos movimenta.

\title{
Palavra com temperatura: alguns pontos entre dança e poesia
}

\author{
Palavra viva \\ Palavra com temperatura, palavra \\ Que se produz \\ Muda \\ Feita de luz mais que de vento, palavra
}

(HOLLANDA, 1995)

"Uma palavra". A canção de Chico Buarque de Hollanda me mobiliza há bastante tempo, mas, lendo "Pensamento, corpo e devir", de Suely Rolnik, essa letra me veio à cabeça algumas vezes, especialmente, no tópico "são as marcas que escrevem”. O texto de Rolnik afeta o corpo de quem lê numa costura sinestésica de cores, sons e fôlego, de tal modo que tecer comentário sobre essa escrita nada mais é do que abrir espaço para o silêncio - agora, em sentidos outros - e para as próprias citações:

Escrever é esculpir com palavras a matéria-prima do tempo, onde não há separação entre a matéria-prima e a escultura, pois o tempo não existe senão esculpido em um corpo, que neste caso é o da escrita, e o que se escreve não existe senão como verdade do tempo. (...) escrever é fazer letra para a música do tempo. (ROLNIK, 1993, p. 9) 
Quando mencionei, primeiramente, o silêncio que antecede a escrita - agora, isso se torna mais claro para mim - de fato, não me referia a algo que pudesse significar etapa inerente ao processo criativo da escrita, mas à tensão de produzir textos "sem brilho de uma vitalidade, na medida em que são textos que não encarnam marca alguma, e que na melhor das hipóteses têm um brilho puramente intelectual, de inteligência e/ou erudição" (ROLNIK, 1993, p. 7).

"Palavra com temperatura". Se, em momentos anteriores, a letra de música em questão me provocava certas marcas, noto que estas continuam vivas e, neste ambiente de agora, encontram ressonâncias, se reatualizam, se ressignificam, produzindo-me uma nova diferença. Se por algum tempo o tempo de pausa do trabalho docente - me deparei com um "branco" relativo à minha prática como professora de Português, questionando-me acerca da própria função deste ofício e até suspeitando de um funcionamento preso a convicções, por vezes, "sem brilho de uma vitalidade", oriundas de leituras mesmas, a "palavra com temperatura", afinal, me reorienta de algum modo, porque me explicita a força de escolhas por outros caminhos, outras leituras, fruto, evidentemente, dessas ressonâncias.

Aproveito, então, para resgatar outra passagem do texto:

No visível há uma relação entre um eu e um ou vários outros (...), unidades separáveis e independentes; mas no invisível, o que há é uma textura (ontológica) que vai se fazendo dos fluxos que constituem nossa composição atual, conectandose com outros fluxos, somando-se e esboçando outras composições. (ROLNIK, 1993, p. 2).

Como havia dito antes, minha trajetória por este curso tornou minha "presença" mais poética e, nesse sentido, algumas leituras me lançam a outras - por vezes, referências literárias. A imagem que construo com essa passagem do texto se aproxima da leitura que faço do poema "Tecendo a manhã", de João Cabral de Melo Neto, o qual opto por destacar em sua íntegra a seguir:

Um galo sozinho não tece uma manhã: ele precisará sempre de outros galos. De um que apanhe esse grito que ele e o lance a outro; de um outro galo que apanhe o grito de um galo antes e o lance a outro; e de outros galos que com muitos outros galos se cruzem os fios de sol de seus gritos de galo, para que a manhã, desde uma teia tênue, se vá tecendo, entre todos os galos.

E se encorpando em tela, entre todos, se erguendo tenda, onde entrem todos, se entretendendo para todos, no toldo 
(a manhã) que plana livre de armação.

A manhã, toldo de um tecido tão aéreo

que, tecido, se eleva por si: luz balão.

(MELO NETO, 1994, p. 219)

A textura dos fluxos que se conectam, se somam, esboçando outras composições, me sugere o "tecer desta manhã”, também feito de fluxos, vozes, coletividade, marcas. A propósito, há um processo poético chamado "enjambement" (em português, equivalente a "encavalgamento"), que consiste no desalinhamento da estrutura métrica e sintática de uma composição, isto é, o processo marcado pela continuação do sentido de um verso no verso seguinte, de modo que não é possível compreender cada verso isoladamente, por meio do paralelismo tradicional, mas somente por meio do conjunto, da interseção, dos laços. Neste movimento que vejo e, mais do que isso, sinto, a partir da combinação entre poesia e dança, para mim, ganham maior consistência os sentidos de devir, bem como outros modos de fazer pesquisa.

\section{Tecendo sobre transbordamentos}

- Eu acordei, no fim da noite, com a água escorrendo pelas paredes da minha casa.

- O pior foi comigo. O Rio Maracanã inundou as ruas e eu só consegui atravessar para minha casa depois de meia-noite.

(Relatos de uma tempestade, diálogo entre garçons, verão de 2020, Rio de Janeiro)

Almoçando sozinha em um restaurante da cidade, enquanto buscava espaço e inspiração para a escrita de si, esses relatos sobre uma noite de tempestade, vivências marcadas pelas forças de uma estação do ano, mas, sobretudo, pelos desfalques no planejamento urbano de uma grande cidade, fui instantaneamente motivada a registrar a palavra "transbordamentos" no bloco de notas que estava à mão.

Neste momento, resgatando a palavra encontrada solta no canto da página de anotações, me mobilizo a fazer uma rápida investigação sobre seu significado no dicionário, o que, para minha surpresa, me conduziu novamente ao processo poético: [versificação: m.q. ENJAMBEMENT]. Sobre marcas que permanecem vivas, então, compreendo suas ressonâncias.

$\mathrm{Na}$ intenção de registrar impressões minhas sobre as leituras e debates feitos ao longo do curso, me vejo, em alguns momentos, em postura de autocensura, isto é, tentando evitar a tradução dessas minhas impressões por meio de imagens e metáforas, sob o risco de provocar certos reducionismos a qualquer discussão que valha. No entanto, tal "método" transborda e aqui se faz. Transbordando, vou tecendo sobre transbordamentos. Escrevendo sobre a escrita de si, vou exercitando-a: conteúdo e forma? A hora de uma nova tempestade, depois de um dia ensolarado, se aproxima. Quando o Rio Maracanã transborda, não há 
mais tempo para manter conteúdo e forma intactos. Assim, destaco, resumidamente, alguns pontos que Marisa Vorraber Costa define como pano de fundo para o diálogo entre ciência e o mundo: "pesquisar é uma aventura", "achados de pesquisa são parciais e provisórios", “pesquisar é processo de criação", “o mundo não é de um único jeito", "a neutralidade da pesquisa é uma quimera", "o mundo continua mudando". (cf. COSTA, 2002, p. 151-153). A tempestade, por vezes, é prenunciada por meio de sons e cores que nos assustam, a priori, mas se (des)faz em líquido, que precisa fluir pelo mapa.

\section{Pontos desalinhados com silêncios e vozes: ressonâncias}

Composição básica para a própria existência da música, silêncio e som, ainda que dicotomicamente, estão presentes nas minhas leituras/percepções cíclicas. Em aulas distintas sobre leituras de Foucault, ao longo do curso, das escritas-anotações compartilhadas, destaco uma breve reflexão a partir do debate sobre "Poder e Saber":

\section{Silêncio:}

lugar do não-saber?

"Falta que (me) desencoraja"?

"Necessidade quase existencial

que (me) impele a pensar

que incita a estabelecer

uma relação criadora com a linguagem"?

Silêncio:

lugar do não-dizer?

Hora minha que (me) desencoraja...

Frio na barriga que a Academia, ora, (me) incita

Desde os tempos de escola...

Muitas vozes na turma. Silencio...

Que não sei "assaltar" turnos de fala

Silêncio!

O professor assalta o turno

das vozes que querem falar.

Silêncio.

"Delírio de presunção

Querer falar de um objeto desconhecido

Com um método desconhecido".

Silêncio!

O professor de Português solicita

a tarefa da aula:

Escrevam uma redação de 25 linhas sobre o tema: 
Silêncio.

(Ah...! Não pode ser poesia!)

\section{Para não enlaçar, mas deixar fluir...}

Onde será que isso começa

A correnteza sem paragem

$O$ viajar de uma viagem

A outra viagem que não cessa

(CALCANHOTO, 1992)

Especialmente na voz de Maria Bethânia, a canção "O nome da cidade", composta por Adriana Calcanhoto, me mobiliza a ilustrar a força dessa correnteza de pensamento. São leituras cíclicas sobre a pesquisa e a escrita como construção de si. São imagens que esboçam viagem pela própria cidade, mas com um tipo de olhar estrangeiro. O pensamento como deslocamento.

\section{Pontos sem nó: experimentando espaços de liberdade na pesquisa e na escrita}

Penso que a leitura e a escrita acadêmica precisariam, talvez, ter um pouco o caráter de experiência, de modo que nós, escreventes e leitores, pudéssemos nessa aventura fazer o exercício de pensar, estar simultaneamente dentro e fora de nós mesmos, de viver efetivamente experiências, no sentido de que as coisas que vivemos e produzimos nos abram ao que não somos nós mesmos, vivendo algo que é ao mesmo tempo atividade e passividade - porque nos deixamos atravessar por outras ideias, por outras sensações, por acontecimentos, disponíveis ao que nisso tudo há de arte, de potência criativa. (FISCHER, 2005, p. 128)

Como foi dito, este texto surge a partir de certa provocação lançada numa disciplina da pósgraduação do PPFH: escrever e (com)partilhar textos, sem a preocupação com o formato nem com a vinculação estrita com os respectivos temas de pesquisa, mas que dessem vazão às percepções, às afetações, aos entendimentos produzidos nas mais variadas atividades proporcionadas ao longo do curso: leitura de textos indicados, participação nos Seminários oferecidos pelos professores convidados, bem como nas dinâmicas e trocas que conseguíssemos acionar ao longo dos encontros semanais em sala de aula. Atividades, enfim, que abrissem espaços de liberdade, permitindo deslocar o pensamento, explorar as fronteiras entre a arte, a criação e o cuidado de si, entre a produção de textos acadêmicos e a escrita de si.

A provocação se justifica a partir do entendimento de que mais do que possível, se torna desejável que, no trabalho de investigação científica - e da consequente produção dos textos acadêmicos -, não nos deixemos dominar pelas regras acadêmicas enrijecidas, pelos métodos científicos limitantes, por prescrições que acabam por definir até mesmo como devemos produzir os textos acadêmicos. Neste sentido, o convite-provocação tinha como base algumas apostas. 
Uma delas parte da observação de que nossos textos acadêmicos têm muito a ganhar se nos permitirmos estar presentes neles, se entendemos que temas de pesquisa, autores e leituras escolhidos resultam do modo como nos vinculamos afetiva, profissional e politicamente a eles.

Outra aposta se refere ao processo de investigação conduzido no âmbito de cada projeto de pesquisa, no qual o conhecimento adquirido não deve ter mais importância do que a experiência de conhecer. Traçando um paralelo ao que Kastrup e Gurgel (2019) afirmam, ao falarem da experiência de aprender, o conhecimento “...deixa de ser adquirir um saber sobre o mundo exterior e se torna experimentar afetos, acolher fluxos, criar consistências e perceber resistências, enfim, experimentar diferentes modos de lidar com o conhecimento e de estar no mundo" (p. 69).

Uma terceira aposta, por fim, tem relação com o sentido dado por Foucault para a experiência: aquilo do qual saímos transformados. Mas, como questiona Rosa Fischer (2005): "Em que medida revolucionamos nossa alma, deixamo-nos liberar o pensamento daquilo que já está ali instalado, pensado, silenciosamente, para ir adiante, converter a rota, abandonar a serena atitude de quem legitima o que já sabe?” (p. 136). Para escaparmos à reprodução de modelos teóricos consagrados, é preciso colocar em questão aquilo que tomamos como natural e imutável, estarmos dispostos a estender os limites do que era pensado até então. Para evitar a repetição de fórmulas e formatos conhecidos e tranquilizadores, é necessária certa atitude de abertura, uma disposição para experimentar algo sobre o qual não temos conhecimento suficiente, de maneira a não podermos prever ou controlar seus resultados.

$\mathrm{Na}$ construção deste texto, vários pontos foram reunidos, mas nenhum foi atado. Os autores/pesquisadores ampliaram sua potência criativa, se deixaram atravessar por outras ideias, experimentaram uma escrita viva, pulsante. Inspirados em Foucault (2010), exercitaram o escrever(-se) para não serem mais os mesmos.

\section{Referências}

CALCANHOTO, Adriana. O nome da cidade. Rio de Janeiro: CBS/ Columbia Records, 1992. Disponível em: https://www.vagalume.com.br/adriana-calcanhoto/o-nome-da-cidade.html

COSTA, Maria Vorraber. Agenda para novos pesquisadores. In: COSTA, Maria Vorraber e VEIGANETO, Alfredo. (org.). Caminhos investigativos II: outros modos de pensar e fazer pesquisa em educação. Rio de Janeiro: DP\&A, 2002, p. 143-156.

DELEUZE, Gilles. Conversações. Rio de Janeiro: Editora 34, 1992.

DELEUZE, Gilles. GUATTARI, Félix. Kafka: para uma literatura menor. Lisboa: Assírio \& Alvin, 2003. 
DELEUZE, Gilles. FOUCAULT, Michel. Os Intelectuais e o Poder: conversa entre Michel Foucault e Gilles Deleuze. In: FOUCAULT, Michel. Microfísica do Poder. 25. ed. Rio de Janeiro: Graal, 2008, p. 41-46.

DIAS, Rosimeri de Oliveira e RODRIGUES, Heliana de Barros Conde. (org.). Escritas de Si: Escutas, cartas e formação inventiva de professores entre universidade e escola básica. Rio de Janeiro: Lamparina, 2019.

FISCHER, Rosa Maria Bueno. Escrita acadêmica: arte de assinar o que se lê. In: COSTA, Marisa Vorraber; BUJES, Maria Isabel Edelweiss (org.) Caminhos investigativos III: riscos e possibilidades de pesquisar nas fronteiras. Rio de Janeiro: DP\&A, 2005, p. 117-140.

FISCHER, Rosa Maria Bueno. Foucault revoluciona a pesquisa em educação? In: FISCHER, R. M. B. Trabalhar com Foucault: arqueologia de uma paixão. Belo Horizonte: Autêntica Editora, 2012, p. 99112.

FOUCAULT, Michel. A ordem do discurso. Aula inaugural no Collège de France, pronunciada em 2 de dezembro de 1970. São Paulo, Edições Loyola, 1999.

FOUCAULT, Michel. Poder e Saber. In: FOUCAULT, Michel. Ditos e escritos IV: Estratégia, podersaber. Trad. Vera Lucia Avellar Ribeiro. Rio de Janeiro, Forense Universitária, 2003, p. 223-240.

FOUCAULT, Michel. A escrita de si. In: FOUCAULT, Michel. Ditos e escritos V: Ética, sexualidade e política. MOTTA, Manoel Barros da (Org.). Tradução de Elisa Monteiro e Inês Autran Dourado Barbosa. Rio de Janeiro: Forense Universitária, 2004, p. 144-162.

FOUCAULT, Michel. Hermenêutica do Sujeito. Curso dado no Collège de France, 1981-1982. São Paulo: Martins Fontes, 2006

FOUCAULT, Michel. Conversa com Michel Foucault. In: FOUCAULT, M. Ditos e Escritos VI: Repensar a Política. Rio de Janeiro: Forense Universitária, 2010.

FOUCAULT, Michel. O Belo Perigo: conversa com Claude Boonefoy. Trad. Fernando Scheibe. Rio de Janeiro: Autêntica, 2016.

GIL, Gilberto. Metáfora. Rio de Janeiro: Warner Music Brasil, 1982. Disponível em: https://www.vagalume.com.br/gilberto-gil/metafora.html

HARA, Tony. Ensaios sobre a singularidade. São Paulo: Intermeios; Londrina: Kan Editora, 2012.

HOLLANDA, Chico Buarque de. Morena de Angola. Rio de Janeiro: EMI-Odeon, 1980. Disponível em: https://www.vagalume.com.br/chico-buarque/morena-de-angola.html

HOLLANDA, Chico Buarque de. Uma palavra. Rio de Janeiro: Sony \& BMG, 1995. Disponível em: https://www.vagalume.com.br/chico-buarque/uma-palavra.html

JESUS, C. M. de. Quarto de despejo - diário de uma favelada. São Paulo: Ática, 2001.

KASTRUP, Virgínia. e GURGEL, Verônica. O papel da escrita na formação de professores e o problema da coermergência. In: DIAS, Rosimeri. e RODRIGUES, Heliana de Barros Conde (orgs.). Escritas de Si: Escutas, cartas e formação inventiva de professores entre universidade e escola básica. Rio de Janeiro: Lamparina, 2019, p. 60-71.

LARROSA, Jorge. Tecnologias do eu e educação. In: SILVA, Tomaz Tadeu. O sujeito da educação. Petrópolis: Vozes, 1994, p. 35-86.

LARROSA, Jorge. A operação ensaio: sobre o ensaiar e o ensaiar-se no pensamento, na escrita e na vida. In: Educação \& Realidade, v. 29, p. 27-43, jan./jun. 2004.

LARROSA, Jorge. Tremores: escritos sobre a experiência. Belo Horizonte: Autêntica Editora, 2015. 
MELO NETO, João Cabral de. A Educação pela pedra. Rio de Janeiro: Nova Aguilar, 1994.

MOSÉ, Viviane. Calor. Rio de Janeiro: Usina de Pensamento, 2017.

Ó, Jorge Ramos. do. Fazer a Mão - por uma escrita inventiva na universidade. Lisboa: Edições do Saguão, 2019.

PETERS, Michael. Pós-estruturalismo e filosofia da diferença. Belo Horizonte: Autêntica, 2000.

RAMOS, Graciliano. Linhas Tortas. São Paulo: Record, 2005.

RODRIGUES, Heliana de Barros Conde. Um dia, talvez, não se saberá mais o que foi o currículo - Ensaio a partir de uma retro-profecia à maneira foucaultina. In: FERRAÇO, Carlos Eduardo; RANGEL, Iguatemi Santos; CARVALHO, Janete Magalhães; NUNES, Kezia Rodrigues. (Orgs). Diferentes perspectivas de currículo na atualidade. Petrópolis: De Petrus, 2015.

ROLNIK, Suely. Pensamento, corpo e devir - uma perspectiva ético/estético/política no trabalho acadêmico. In: Caderno de Subjetividade: Núcleo de Estudos e Pesquisas da Subjetividade do Programa de Estudos Pós-Graduados em Psicologia Clínica da PUCSP. São Paulo, v. 1, n. 2, p. 24151, fev./set. 1993.

SAUSSURE, Ferdinand. Curso de linguística geral. 26ª ed. Tradução de Antônio Chelini, José Paulo Paes e Izidoro Blikstein. São Paulo: Cultrix: 1995.

Recebido em: 30/04/2020

Revisões Requeridas em: 17/06/2020

Aceito em: 30/07/2020

Notas

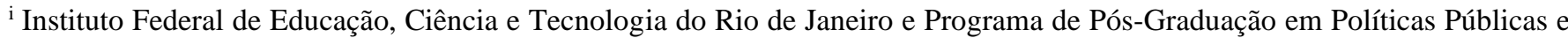
Formação Humana da Universidade do Estado do Rio de Janeiro - E-mail: awerneckrusso@ gmail.com - Rio de Janeiro ORCID:https://orcid.org/0000-0001-5877-3303
}

ii Universidade Federal Rural do Rio de Janeiro: Colégio Técnico e Programa de Pós-Graduação em Políticas Públicas e Formação Humana da Universidade do Estado do Rio de Janeiro - E-mail: karinebastos@terra.com.br - Rio de Janeiro ORCID:https://orcid.org/0000-0002-5921-4498

iii Universidade do Estado do Rio de Janeiro: Faculdade de Educação da Baixada Fluminense e Programa de Pós-Graduação em Políticas Públicas e Formação Humana - E-mail: saleh.amado@ gmail.com - Rio de Janeiro - ORCID: https://orcid.org/00000002-4629-867X

iv A expressão foi inspirada na produção de Foucault (2010, p. 290): "Escrevo para mudar a mim mesmo e não mais pensar a mesma coisa".

v Carolina Maria de Jesus, moradora da favela do Canindé/São Paulo na década de 1930, trabalhava como catadora de papel e, nas horas vagas, usava os cadernos que encontrava, em meio ao material que recolhia, para registrar o seu cotidiano. Um de seus cadernos/diários deu origem ao seu famoso livro Quarto de Despejo - Diário de uma Favelada (1960). A história de Carolina é contada por Tom Farias (2017) no livro Carolina - Uma Biografia.

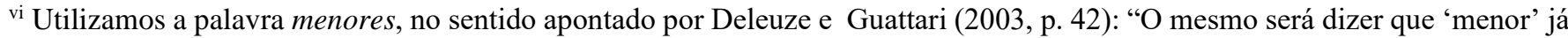
não qualifica certas literaturas, mas as condições revolucionárias de qualquer literatura no seio daquela a que se chama grande (ou estabelecida)".

${ }^{\text {vii }}$ Produzida/provocada a partir da leitura do texto A escrita de si de Michel Foucault (2004). 
viii Segundo Foucault (1995), "mais que de um "antagonismo" essencial, seria melhor falar de uma "agonística" - de uma relação que é, ao mesmo tempo, de incitação recíproca e de luta; trata-se menos de uma oposição termo a termo que os bloqueia um em face do outro, e mais de uma provocação permanente" (p. 244-245).

ix A obra, adquirida por uma das autoras deste artigo, serviu como um intercessor, à maneira deleuziana (1992), na produção das anotações em aula e na produção deste texto.

${ }^{x}$ Obra produzida pelo Grupo Matizes Dumont (www.matizesdumont.com).

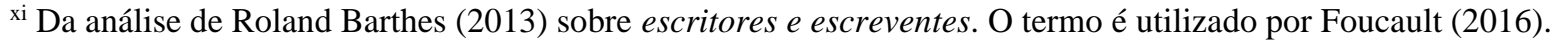

xii O termo é utilizado em filiação a Guattari (1996): "Ele é o conjunto de projetos e representações nos quais vai desembocar, pragmaticamente, toda uma série de comportamentos, de investimentos, nos tempos e nos espaços sociais, culturais, estéticos, cognitivos" (p. 323).

xiii Expressão usada por Foucault (2016) em uma entrevista, cuja temática principal era a relação afetiva do pesquisador com a arte da escrita, concedida a Claude Bonnefoy.

xiv Para Deleuze (1988), “os afectos são os devires. São devires que transbordam daquele que passa por eles, que excedem as forças daquele que passa por eles. O afecto é isso.

${ }^{\mathrm{xv}}$ Prof $^{\mathrm{a}}$. Dr ${ }^{\mathrm{a}}$. Kátia Aguiar é psicóloga, pesquisadora e professora do Departamento de Psicologia, vinculado ao Programa de Pós-Graduação em Psicologia da Universidade Federal Fluminense (UFF).

${ }^{\text {xvi }}$ O Prof. Dr. Jorge Ramos do Ó (Universidade de Lisboa/Portugal) proferiu, entre 02 e 05 de agosto de 2019, na UERJ, o Ciclo de Conferências - Por uma escrita acadêmica anti-normativa e inventiva.

xvii A imagem de uma caixa de artesanatos de onde "tiramos" os instrumentos com os quais vamos manusear o texto é produzida com a declaração de Deleuze em diálogo com Foucault: "uma teoria é como uma caixa de ferramentas.[...] É preciso que sirva, é preciso que funcione. E não para si mesma. [...] Não se refaz uma teoria, fazem-se outras; há outras a serem feitas (DELEUZE; FOUCAULT, 2008, p. 71).”

xviii Produzido/provocado a partir da leitura do texto: A ordem do discurso. Aula inaugural no Collège de France, pronunciada em 2 de dezembro de 1970. (FOUCAULT,1999).

${ }^{\text {xix }}$ Larrosa, 1994.

${ }^{x x}$ Um exame de consciência inserido na ordem da espiritualidade cristã: "deves olhar-te a fim de detectar em ti os vestígios da concupiscência e expor, explorar os segredos de tua consciência” (FOUCAULT. 2006, p. 267-268).

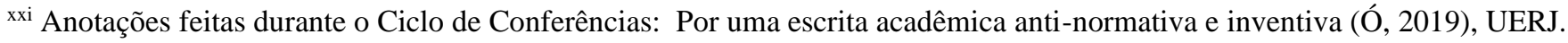

